\title{
Design and practice of a comprehensively functional integrated management information system for major construction
}

\section{Yuling Liu, Xiaoping Wang, Yuhui Zhu, Lanlan Fei}

Yuling Liu, Xiaoping Wang, Yuhui Zhu, Lanlan Fei, "Design and practice of a comprehensively functional integrated management information system for major construction," Proc. SPIE 10452, 14th Conference on Education and Training in Optics and Photonics: ETOP 2017, 1045235 (16 August 2017); doi: $10.1117 / 12.2270962$

SPIE Event: 14th Conference on Education and Training in Optics and Photonics, ETOP 2017, 2017, Hangzhou, China 


\title{
Design and Practice of a Comprehensively Functional Integrated Management Information System for Major Construction
}

\author{
Yuling Liu, Xiaoping Wang, Yuhui Zhu, Lanlan Fei \\ College of Optical Science and Engineering, Zhejiang Univ., China
}

Key words: Management Information System, Major construction, Process Management, Education quality

Abstract: This paper introduces a Comprehensively Functional Integrated Management Information System designed for the Optical Engineering Major by the College of Optical Science and Engineering, Zhejiang University, which combines the functions of teaching, students learning, educational assessment and management. The system consists of 5 modules, major overview, online curriculum, experiment teaching management, graduation project management and teaching quality feedback. The major overview module introduces the development history, training program, curriculums and experiment syllabus and teaching achievements of optical engineering major in Zhejiang University. The Management Information System is convenient for students to learn in a mobile and personalized way. The online curriculum module makes it very easy for teachers to setup a website for new curriculums. On the website, teachers can help students on their problems about the curriculums in time and collect their homework online. The experiment teaching management module and the graduation project management module enables the students to fulfill their experiment process and graduation thesis under the help of their supervisors. Before students take an experiment in the lab, they must pass the pre-experiment quiz on the corresponding module. After the experiment, students need to submit the experiment report to the web server. Moreover, the module contains experiment process video recordings, which are very helpful to improve the effect of the experiment education. The management of the entire process of a student's graduation program, including the project selection, mid-term inspection, progress report of every two weeks, final thesis, et al, is completed by the graduation project management module. The teaching quality feedback module is not only 
helpful for teachers to know whether the education effect of curriculum is good or not, but also helpful for the administrators of the college to know whether the design of syllabus is reasonable or not. The Management Information System changes the management object from the education results to the entire education processes. And it improves the efficiency of the management. It provides an effective method to promote curriculum construction management by supervision and evaluation, which improves students' learning outcomes and the quality of curriculums. As a result, it promotes the quality system of education obviously.

\section{Introduction}

With the rapid development of Internet information technology, people's life style and learning style have undergone profound changes. Setting up an integrated management information system for Optical Engineering major which combines the Internet information technology with the professional curriculum arrangement, and the students cultivation and education, is very necessary to promote teaching reform and improve the quality of student training.

This paper introduces the design and development of a one-stop management information system for Optical Engineering major to improve the quality of major curriculum arrangement, the students training and the level of teaching management. The system combines the function of teaching, students learning, educational assessment and management. The system can provide the approximate content to students, teachers, administrators and visitors, respectively. Students can get all the information about their study in the university, including the training program, curriculum requirements and course materials. Based on these contents, they can decide their favorite way to study. Faculties can create a new curriculum website which integrates their teaching methodologies, innovation ideas and course materials in an easy and fast way by exploring the templates prefabricated in the management system. Moreover, the curriculum website can achieve the students' feedback about the learning effect in real time. The abundance materials of the curriculum and powerful functions of the curriculum website turn the education process from "teaching oriented" to "learning oriented", from "learning in the class" to "learning anywhere". 
Administrators can learn the situation about curriculum construction, teaching reforms and students learning outcomes in time. For the experiments and graduation projects, the management system provides the information and instructions needed during the entire processes. It changes the focus of education from the result to the whole process of teaching and learning. The management information system sheds light on an effective way to promote the improvement of educational quality. Moreover, it could ensure the rationality of the major curriculum arrangement and keep a good continuity of the educational reform.

\section{Design of the management information system}

The management information system for Optical Engineering Major consists of 5 modules: major introduction, online curriculum, experiment teaching management, graduation project management and teaching quality feedback. The schematic of the system is shown in Figure 1. 


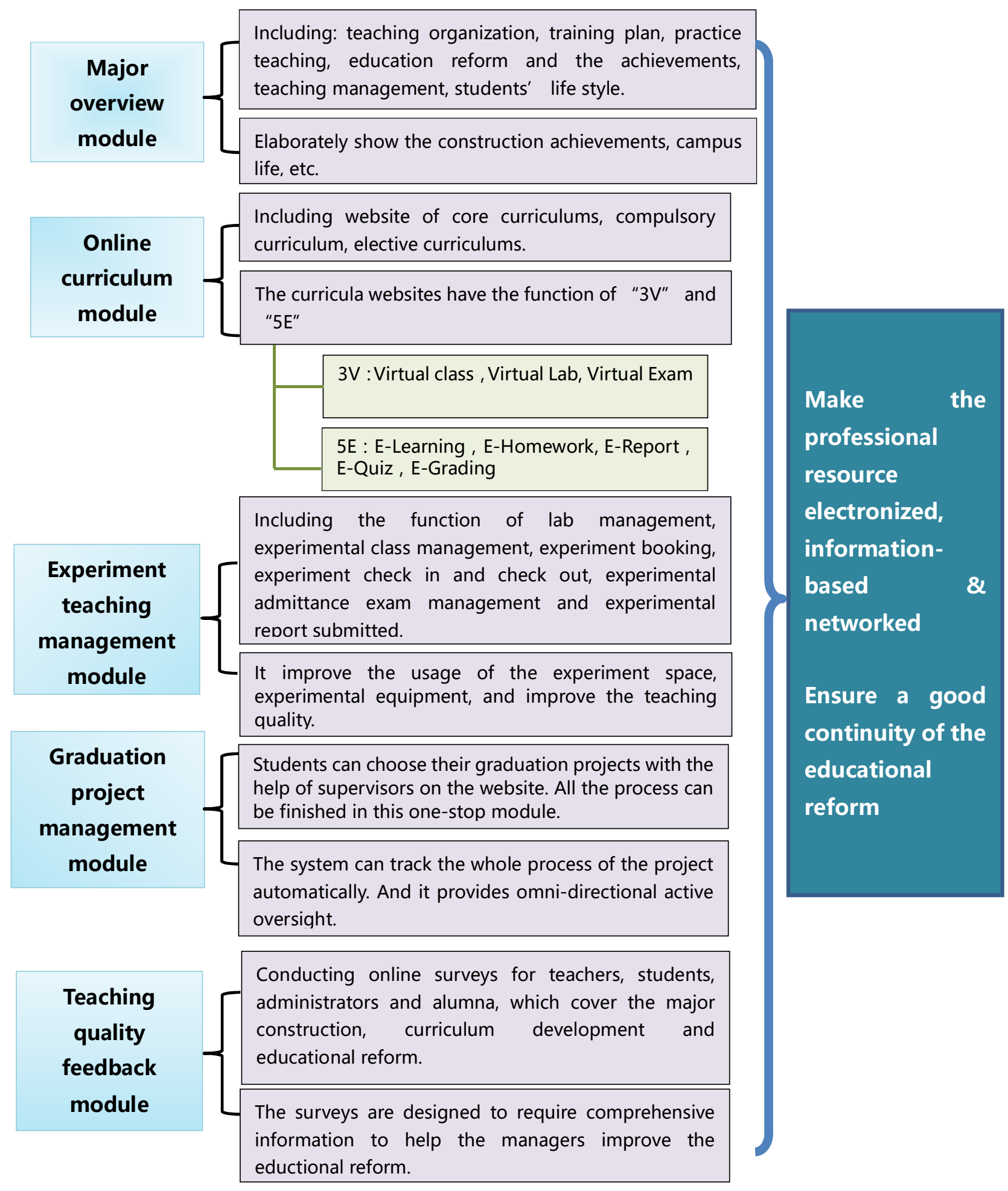

Fig.1 Schematic of comprehensively functional integrated management information system 


\section{(1) Major overview module}

The major overview module includes major introduction, education organization, training program, practice education, teaching reformation and achievements, teaching managements and students' life style.

The "major introduction" section introduces the development history, admission scale. The "training program" section lists the major training program over the years and teaching plans, including the courses introduction, curriculum outline, the syllabus and the teaching design, etc. The "teaching organization" section introduces the faculty members, teaching research groups and courses group. The teaching research activity held by the college and the courses symposium are displayed on the website. The "practice education" section shows the teaching activities arrangement and achievements of all kinds of practice program, such as the Scientific Research Training Program(SRTP), the Optical Research Family Program, the Opto-electronic design competition, the Opto-electronic forum, innovation programs and internships on and off campus. The "educational reform and achievement" section introduces the reforms activities and the achievements acquired in the students' cultivation. The summaries and the achievements are displayed on the web, including the education reform projects, published papers and teaching achievements. The "teaching management" section provides a brief introduction to the outlines of the teaching committee, summary of the undergraduate education and the seminar materials. It also provides us with teaching related templates and forms, making it easy for teachers to review materials over the years. The "students' life style" section introduces our attainments of talents cultivation, including awards and honors, the Family of Students' Quality, the SQTP, the Opto-Electronics Festival, journals published by our college and international exchange projects.

The major overview module gives an complete presentation of the development and construction of the department. We keep accumulating the teaching resources, attainments and excellent works of students. This module makes a platform for students to learn from each other and provides the basis for the development of freshmen. 


\section{(2) Online curriculum module}

The online curriculum module includes all the Opto-Electronics related core courses, compulsory courses, optional courses and practical courses. All these courses use the same IP, which is very convenient for students and teachers in Zhejiang University to visit the websites with their ZJU passwords. The platform connects well with other information systems. For example, teachers can get the roster of their classes from educational administration network. The data of the platform, like the teaching process and scores, centralizes at the server and can be used for secondary development. Students who log in the system can visit all the resources.

The online curriculum module has a library of teaching templates. The number of sections and subtitles is flexible regarding different classes. For example, a website can be constructed with the following sections: Course Home, Theory Teaching, Practice Teaching, Interactive Management, Autonomous Learning, Student Life Style, Online Lab, Virtual Laboratory, Online Communication, Project Teaching, Simulation Teaching, Teaching Resources, Internship Contents, Internship Characteristics, Album of Teachers and Students. For new courses, the lecturer can establish the curriculum's homepage with the help of our library in a short time.

Users are classified into five levels according to their responsibility: administrator, Class Administrator, Teachers/Teaching Assistants, Students, Visitors. Different users have different permission levels to ensure reliable operation.

The online curriculum module has the function of $3 \mathrm{~V}$ Virtual Teaching and $5 E$ Aided Teaching Environment.

3V Virtual Teaching Environment consist of Virtual Class, Virtual Lab and Virtual Exam. Virtual Class include class videos, class flash, experimental videos, etc. Students can review all the contents of the lessons from the website. With Virtual Lab, students can perform simulation experiments, like building circuit or optical arrangement, in order to improve experimental scheme before getting into the lab. Virtual Exam refers to the Exam Center on the platform. Students are allowed to perform self-assessment using the model exam paper.

5E Aided Teaching Environment consist of E-Learning, E-Homework, E-Report, E-Quiz and E-Grading. E-Learning includes teaching courseware, flash, course 
materials, instructions and explanations for the exercise and extensive reading information to meet the needs of students. The assignment, upload, review and download of coursework can be done through E-Homework. E-Report makes it easy to upload experimental report and summary, course project design application, project summary, presentation. E-Grading can help teachers to review submitted reports. The "Online Communication" function breaks the limitation of space and time for communications between teachers and students.

The online curriculum module integrates three thoughts of educational reform, which are, from "teaching oriented" to "learning oriented", from "learning in the class" to "learning anywhere", from "result-based-evaluation" to "whole-process-based evaluation". These changes meet various needs and habits of modern undergraduates. The online communication provides new approaches for interaction between students and teachers.

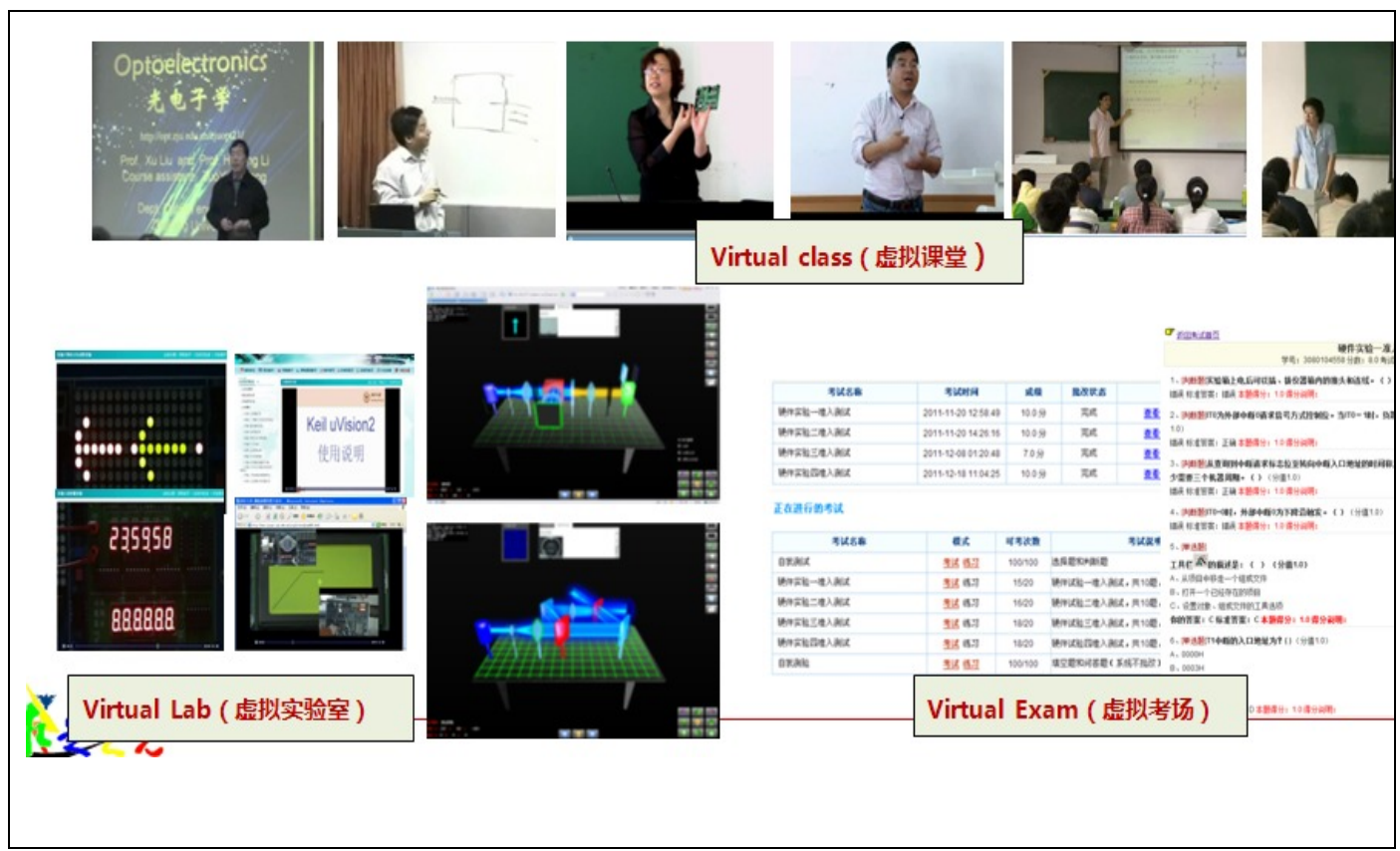




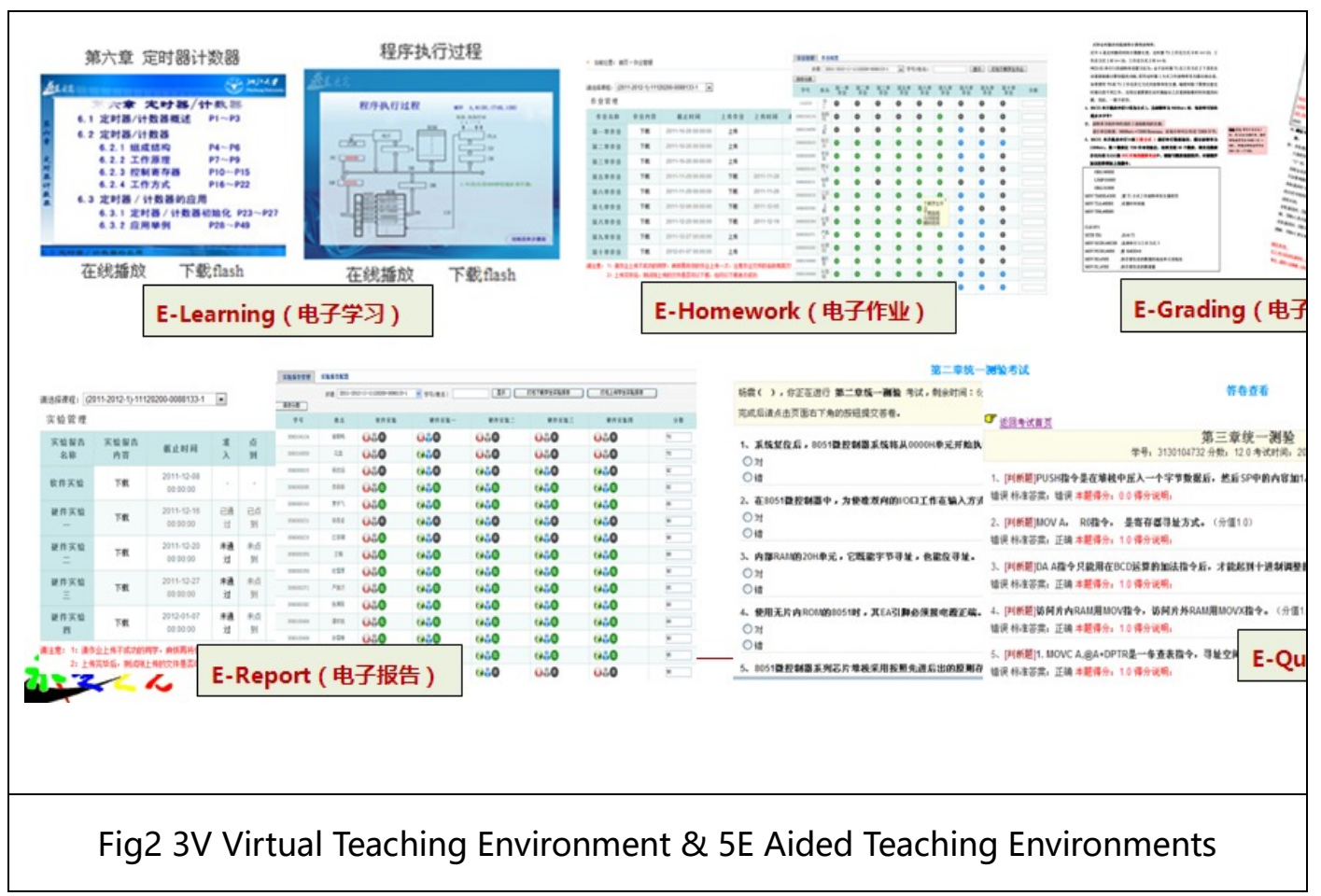

\section{(3) Experiment teaching management module}

The experiment teaching management module includes functions of lab management, experimental courses management, experimental projects management, experimental appointment, experimental records (check-in \& check-out), experimental admission test and upload experimental reports online. The system can improve the usage of experimental setups and supervise their preparation for an experiment.

The experimental appointment section displays the available experiment lists and schedule. Students can make appointments based on their own schedule. For some engineering courses, there is not enough equipment for all the students to perform the experiments at the same time. Taking advantage of this function, we can achieve high usage of the expensive facilities and break the site limitation.

The function of experimental admission test interacts with the course platform. Students must pass the test to get the permission of performing experiments. In this way, they are ensured better preparations before doing experiments, which is necessary to promote their efficiency. The time record function helps record the time students spend on the experiment. Students are allowed to upload their report only if the basic time requirement is met. 


\section{(4) Graduation project management module}

Graduation project takes a whole semester. Different from teaching process, students don't get together at classroom and do everything under teachers' guidance. As a result, it is often the case that communication and guidance are missed during the process of graduation projects. To make the matter even worse, some undergraduates only pay attention to thesis proposal and defense to get a good score, but ignore the research process, which makes the projects meaningless.

Net-based graduation project system digitize every step, such as declaration, topic selection, proposal, medium-term inspection and defense. The graduation project system requires students and their supervisors report progress and requirements every 2 weeks, respectively. In this way, cases that undergraduates get to work right before deadlines or advisors are too busy to give guidance can be avoided. Progress of every project is clear at a glance to administrators, advisors and undergraduates.

The graduation project management module makes it possible for administrators to set different periods due to the overall arrangement. According to the set, the system will automatically remind students and teachers for related operation. This can urge students to implement their projects step by step. Students are required to fill the online reports. Teachers can check the progress of the project online and review the papers through concealed evaluation system. Head of every institute can supervise the project process of the related students conveniently. Administrators from colleges can implement summary and management. All these steps can help us improve the efficiency of management.

\section{(5) Teaching quality feedback module}

The main body of education is students. The students are not only the beneficiaries of teaching reform, but also the most reliable judges. To understand the effect of major construction and teaching reform, adjust the reform strategy in time, and promote the talent cultivation quality, teaching quality feedback module provides the all-round education and teaching investigations to get feedbacks about the pros and cons on the educational works from all participants (including teachers, 
students, administrators and alumni). After being analysed and researched, the feedbacks could bring new ideas to promote the educational reform and improve the quality of talent cultivation.

The teaching quality feedback module has the functions of question database management, subject management, project management, survey object management, and the survey result analysis. The system can conduct educational surveys to different-graded students, seniors, five-year alumni and ten-year alumni. Through different question databases, we can collect their response and advises on education program, teaching methods, teaching environment, educational reform and major development.

The course investigation section in the teaching quality feedback module investigates students' opinions about course contents, teaching methods, teaching resources and teachers. These feedbacks are collected and send to teachers, making it possible for teachers to make timely adjustment.

\section{Achievements of the management information system for major}

\section{construction}

The management information system for major construction not only includes all the digital information of major construction, but also integrates education reform thoughts of teaching, learning, management and assessment.

Teachers, students, administrators, and visitors can get what they need from the system. Teacher can understand the situation of professional and curriculum construction and find the weakness in time. This will motivate teachers to achieve self-improvement. Students can get an understanding of an overall picture of major development, as well as achievement of the seniors. Student and alumni survey results provide timely feedback and advice for major construction and teaching reform. It also strongly promote the development of the professional. The system makes administrators' job factual and makes the management more standardized and efficient. With the system, a benign circulation consists of the service, management and evaluation is established. It's a powerful mean for implementation of educational reform, promoting the good traditions of the major construction, the continuous improvement of education quality and management level. 
Since 2010, the management information system is widely used by more than 2000 students from 10 colleges in Zhejiang University. It is now an important educational information database for administrators, teachers and students in the College of Optical Science and Engineering, Zhejiang University. It also serves as a helper for students and has positive impact on major construction and teaching reform, improvement of the personnel training quality and enhancement of the education management level. 